\title{
Contribution of a Mesocorticolimbic Subcircuit to Drug Context-Induced Reinstatement of Cocaine-Seeking Behavior in Rats
}

\author{
Heather C Lasseter ${ }^{1,2}$, Xiaohu Xie ${ }^{1,2}$, Amy A Arguello', Audrey M Wells', Matthew A Hodges' and \\ Rita A Fuchs*,I \\ 'Department of Psychology, University of North Carolina, Chapel Hill, NC, USA
}

\begin{abstract}
Cocaine-seeking behavior triggered by drug-paired environmental context exposure is dependent on orbitofrontal cortex (OFC)basolateral amygdala (BLA) interactions. Here, we present evidence supporting the hypothesis that dopaminergic input from the ventral tegmental area (VTA) to the OFC critically regulates these interactions. In experiment I, we employed site-specific pharmacological manipulations to show that dopamine DI-like receptor stimulation in the OFC is required for drug context-induced reinstatement of cocaine-seeking behavior following extinction training in an alternate context. Intra-OFC pretreatment with the dopamine DI-like receptor antagonist, SCH23390, dose-dependently attenuated cocaine-seeking behavior in an anatomically selective manner, without altering motor performance. Furthermore, the effects of SCH23390 could be surmounted by co-administration of a sub-threshold dose of the DI-like receptor agonist, SKF81297. In experiment 2, we examined effects of DI-like receptor antagonism in the OFC on OFC-BLA interactions using a functional disconnection manipulation. Unilateral $\mathrm{SCH} 23390$ administration into the OFC plus GABA agonist-induced neural inactivation of the contralateral or ipsilateral BLA disrupted drug context-induced cocaine-seeking behavior relative to vehicle, while independent unilateral manipulations of these brain regions were without effect. Finally, in experiment 3, we used fluorescent retrograde tracers to demonstrate that the VTA, but not the substantia nigra, sends dense intra- and interhemispheric projections to the OFC, which in turn has reciprocal bi-hemispheric connections with the BLA. These findings support that dopaminergic input from the VTA, via dopamine DI-like receptor stimulation in the OFC, is required for OFC-BLA functional interactions. Thus, a VTA-OFC-BLA neural circuit promotes drug context-induced motivated behavior.

Neuropsychopharmacology (20I4) 39, 660-669; doi:I0.1038/npp.2013.249; published online I6 October 20I3
\end{abstract}

Keywords: relapse; cocaine; dopamine; orbitofrontal cortex; amygdale; ventral tegmental area

\section{INTRODUCTION}

The lateral orbitofrontal cortex (OFC) and basolateral amygdala (BLA) are integral components of the mesocorticolimbic neural circuitry that regulates the ability of cocaine-paired discrete or contextual cues to trigger powerful drug craving and drug-seeking behaviors. In abstinent cocaine users, exposure to cocaine-paired environmental stimuli elicits neural activation in the OFC and BLA and concomitant increase in cocaine craving (Childress et al, 1999; Duncan et al, 2007; Grant et al, 1996; London et al, 1999). In laboratory animals, OFC or BLA functional inactivation inhibits drug context-induced cocaine-seeking behavior (Fuchs et al, 2005; Lasseter et al, 2009). Moreover,

*Correspondence: Dr RA Fuchs, Department of Psychology, University of North Carolina, CB no. 3270, Davie Hall, Chapel Hill, NC 27599 3270, USA, Tel: +919 843 9|12, Fax: +919 962 2537,

E-mail: rfuchs@unc.edu

${ }^{2}$ These authors contributed equally to this work.

Received 9 May 2013; revised 28 August 2013; accepted 29 August 2013; accepted article preview online 20 September 2013 the OFC and BLA display functional interdependence in the control of drug context-induced cocaine-seeking behavior such that interhemispheric or intrahemispheric disconnection of the OFC and BLA attenuates this behavior (Lasseter et al, 2011). However, the larger neural circuitry within which the OFC and BLA interact to promote drug contextinduced goal-directed behaviors remains to be investigated.

Emerging evidence suggests that dopaminergic neurotransmission in the OFC may be necessary for a drug-paired context to produce cocaine-seeking behavior. The ventral tegmental area (VTA) sends dopaminergic projections to the OFC (Berger et al, 1991; Dunnett and Robbins, 1992; Frankle et al, 2006; Geisler et al, 2007; Sesack and Grace, 2010). Furthermore, dopaminergic neurotransmission in the frontal cortices critically regulates higher-order cognitive function, including reward-related processing by the OFC that likely facilitates cocaine-seeking behavior (Cetin et al, 2004; Dalley et al, 2004; Kheramin et al, 2004; Ragozzino et al, 1999; Ward et al, 2009; Winter et al, 2009). Systemic dopamine D1-like receptor antagonism impairs drug context-induced cocaine-seeking behavior (Crombag 
et al, 2002). However, to date, no study has ascertained whether dopaminergic neurotransmission in the OFC is critical for drug context-induced cocaine-seeking behavior.

Based on the above findings, we hypothesized that input from the VTA to the OFC-via dopamine D1-like receptor stimulation-regulates interactions between the OFC and BLA that promote the motivational effects of cocaine-paired environmental stimuli on drug-seeking behavior. To test this hypothesis, in experiment 1 , we examined the effects of bilateral dopamine D1-like receptor antagonism in the OFC and in the adjacent primary/secondary motor cortex (M1/2, anatomical control region) on drug context-induced cocaine-seeking behavior and on indices of instrumental and general motor performance. We confirmed the receptor specificity of the effects on cocaine-seeking behavior by co-administering a dopamine D1-like receptor agonist. In experiment 2, we evaluated the effects of VTA-OFC-BLA functional disconnection and control manipulations on drug context-induced cocaine seeking. Finally, in experiment 3 , we used retrograde fluorescent tracers to verify that the requisite anatomical connections exist to form a putative VTA-OFC-BLA circuit.

\section{MATERIALS AND METHODS}

\section{Animals}

Male Sprague-Dawley rats (250-300 g; Charles River, Wilmington, MA, USA) were housed individually in a climate-controlled vivarium on reversed light-dark cycle. Rats received $20-25 \mathrm{~g}$ of rat chow per day with water available ad libitum. Animal housing and treatment protocols followed the Guide for the Care and Use of Laboratory Animals (National Research Council, USA, 2011).

\section{Food Training and Surgery}

In experiments 1 and 2 , rats $(N=90)$ were trained to lever press under a fixed-ratio 1 (FR-1) food reinforcement schedule during a single overnight session in order to facilitate subsequent drug self-administration training (Fuchs et al, 2007). The operant conditioning chambers and levers used during food training were different from those used later for drug self-administration and extinction training. Forty-eight hours later, surgical anesthesia was induced using ketamine hydrochloride and xylazine (66.6 and $1.33 \mathrm{mg} / \mathrm{kg}$, i.p., respectively) with additional dosing applied, as needed, in order to maintain full anesthesia throughout the surgery. Rats were surgically implanted with intravenous jugular catheters and 26-gauge stainless steel guide cannulae (plastics one) aimed bilaterally or unilaterally at the OFC $(+3.5 \mathrm{~mm} \mathrm{AP},+/-3.0 \mathrm{~mm} \mathrm{ML},-3.4 \mathrm{~mm} \mathrm{DV}$, from bregma), $\mathrm{M} 1 / 2(+3.5 \mathrm{~mm} \mathrm{AP},+/-3.0 \mathrm{~mm} \mathrm{ML}$, $-2.4 \mathrm{~mm} \mathrm{DV}$, from bregma), or BLA $(-2.7 \mathrm{~mm} \mathrm{AP},+1$ $-5.2 \mathrm{~mm} \mathrm{ML},-6.7 \mathrm{~mm} \mathrm{DV}$, from bregma).

\section{Cocaine Self-Administration and Extinction Training}

After surgical recovery, rats were trained to press one (active) lever under an FR-1 schedule of cocaine reinforcement (cocaine hydrochloride, $0.15 \mathrm{mg} / 0.05 \mathrm{ml}$ infusion, i.v.; NIDA, Research Triangle Park, NC) with a $20 \mathrm{~s}$ timeout a

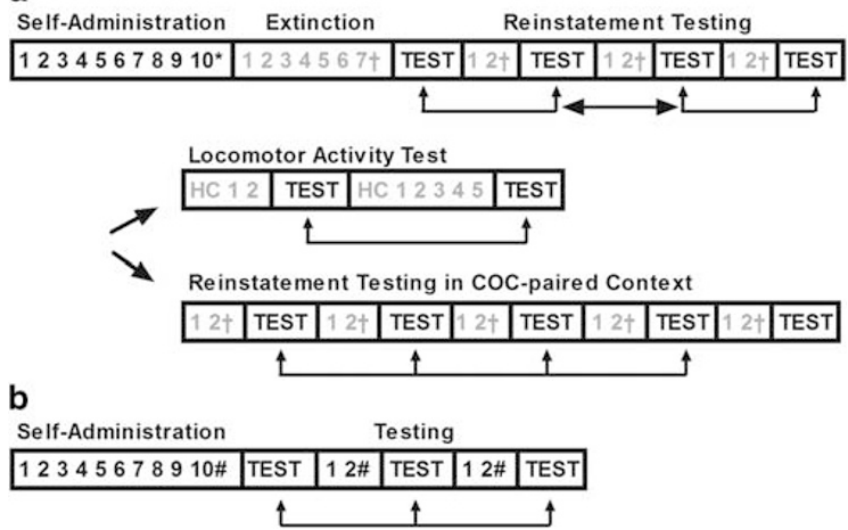

Figure I Schematic representation of (a) the timeline for the drug context-induced reinstatement experiments and (b) for the foodreinforced instrumental control experiment. In the reinstatement experiments (a), rats had to reach acquisition (*Represents $\geqslant 10$ cocaine infusions per session for minimum 10 sessions) and extinction ( ${ }^{\dagger}$ Represents $\leqslant 25$ active lever presses per session for two consecutive sessions) criteria before drug context-induced reinstatement testing. After the fourth drug context-induced reinstatement test session, in one subgroup of rats, photobeam interruptions were assessed in a novel context. Before each locomotor activity test, the rats remained in their home cages $(\mathrm{HC})$. In the other subgroup of rats, reinstatement of extinguished cocaine-seeking behavior was assessed in the previously cocaine-paired context following agonist administration (tests $\mid-4$ ) and following cocaine or saline priming (test 5). In the food-reinforced instrumental control experiment, rats had to reach a stability criterion ( ${ }^{\#}$ Represents $<10 \%$ variability in food-reinforced active lever presses on two consecutive sessions) before testing. In each experiment, the order of drug pretreatments (vehicle; VEH first, agonist and/or antagonist dose first) and context exposure (cocaine-paired context first, extinction context first) were counterbalanced, when appropriate, across tests sessions as indicated by the arrows.

period (see experimental timeline in Figure 1). Responses on a second (inactive) lever were recorded but had no scheduled consequences. Training occurred during $2 \mathrm{~h}$ sessions in operant conditioning chambers configured to form one of two distinct contexts (contexts 1 and 2, described in Supplementary Methods). Rats that failed to obtain $\geqslant 10$ cocaine infusions/session on $\geqslant 10$ sessions were eliminated from the experiment. The remaining rats received daily $2 \mathrm{~h}$ extinction training sessions in the alternate context (context 1 or 2). During the sessions, lever responses were recorded but had no scheduled consequences. Before session 4, rats were adapted to the intracranial microinfusion procedure, as described previously (Lasseter et al, 2011). Rats that reached an extinction criterion ( $\geqslant 7$ sessions with $\leqslant 25$ active lever responses/session during the last two sessions) were used for subsequent reinstatement testing.

\section{Reinstatement Testing}

Lever pressing was assessed in the cocaine-paired and extinction contexts during $1 \mathrm{~h}$ test sessions. Immediately before testing, rats received intracranial $(0.5 \mu \mathrm{l} /$ hemisphere $)$ or systemic pretreatment with one dose of an antagonist and/or agonist or vehicle (VEH), as described below. Intracranial microinfusions were delivered via $33 \mathrm{Ga}$ stainless steel injection cannulae ( $2 \mathrm{~mm}$ extension past the guide cannula; plastics one) over $2 \mathrm{~min}$. The order of the two 
pretreatment doses and testing contexts was counterbalanced across test sessions based on cocaine history (see experimental timeline in Figure 1a). Between test sessions, rats received additional daily extinction training sessions until they re-obtained the extinction criterion.

In experiment 1 , we evaluated whether D1-like receptor stimulation was required in the OFC or $\mathrm{M} 1 / 2$ for drug context-induced cocaine seeking. Rats received bilateral pretreatment with phosphate-buffered saline $\mathrm{VEH}$ or the dopamine D1-like receptor antagonist, SCH23390, into the OFC ( 0.02 or $0.2 \mu \mathrm{g}$, based on Capriles et al, $2003 ; n=8-10$ / group) or $\mathrm{M} 1 / 2(0.2 \mu \mathrm{g}, n=9)$. To assess the receptor specificity of $\mathrm{SCH} 23390$ effects, additional rats received bilateral intra-OFC pretreatment with $\mathrm{SCH} 23390(0.2 \mu \mathrm{g})$ in combination with $0.1 \%$ dimethyl sulfoxide (DMSO) VEH or the D1-like agonist, SKF81297 (0.1 or $0.3 \mu \mathrm{g}, n=7$ /group). After the fourth test session, responding in this second cohort of rats was extinguished in the cocaine-paired context. We then assessed whether intra-OFC SKF81297 $(0.1,0.3$ or $1.0 \mu \mathrm{g}, n=14)$ was sufficient to reinstate extinguished lever responding in the previously cocainepaired context relative to $\mathrm{VEH}$, using a within-subjects design. Finally, we examined whether the rats retained the capacity for reinstatement after repeated testing by examining whether i.p. cocaine priming ( $10 \mathrm{mg} / \mathrm{kg}, n=7 /$ group) reinstated lever responding relative to $\mathrm{VEH}$, using a between-subjects design.

In experiment 2, we examined whether D1-like receptor stimulation in the OFC controls intrahemispheric and interhemispheric interactions between the OFC and BLA that mediate drug context-induced cocaine-seeking behavior. To bilaterally disrupt intrahemispheric neural communication (Figure 3a), rats $(n=12)$ received unilateral SCH23390 $(0.2 \mu \mathrm{g}$, based on experiment 1$)$ pretreatment into the OFC plus unilateral $\mathrm{GABA}_{\mathrm{B}} / \mathrm{GABA}_{\mathrm{A}}$ receptor agonist cocktail, baclofen + muscimol (BM; 106.8/5.7 ng, respectively; based on the experiment by Lasseter et al (2011)), pretreatment into the contralateral BLA. To bilaterally disrupt interhemispheric communication, additional rats $(n=10)$ received the same pretreatments ipsilaterally. The same rats were also tested following contralateral or ipsilateral VEH pretreatment. Additional control groups were tested following unilateral SCH23390 or VEH pretreatment into the OFC $(n=11)$ or unilateral BM or VEH pretreatment into the BLA $(n=7)$. Based on our previous finding that both intra- and interhemispheric OFC-BLA interactions control drug context-induced cocaine seeking (Lasseter et al, 2011), functional interdependence within the VTA-OFC-BLA circuit was predicted to manifest as a superadditive effect following contralateral or ipsilateral manipulation relative to the effects of separate, unilateral manipulation of each target brain region.

\section{General and Instrumental Motor Behavior}

Intracranial manipulations can produce motor deficits that impair instrumental performance. Hence, the effects of intra-OFC SCH23390 or VEH pretreatment on general locomotor activity (that is, photobeam interruptions) were assessed in a novel context during a 1-h test session, using the rats in experiment 1 ( $n=8-10 /$ group). The effects of the same manipulations on food-reinforced instrumental behavior were assessed in experimentally naïve rats $(n=9)$. These procedures and the experimental timeline are described in Supplementary Methods and Figure 1a and b.

\section{Histology and Data Analysis}

In experiments 1 and 2, rats were overdosed using ketamine/xylazine (66.6 and $1.3 \mathrm{mg} / \mathrm{kg}$ i.v. or 199.8 and $3.9 \mathrm{mg} / \mathrm{kg}$ i.p., respectively, depending on catheter patency). The brains were dissected out and stored in $10 \%$ formaldehyde solution. Coronal sections $(75 \mu \mathrm{m})$ were cut on a vibratome. Cannula placements were examined on cresyl violet-stained (Kodak, Rochester, NY, USA) sections using light microscopy and mapped onto schematics from the rat brain atlas of Paxinos and Watson (1997). Behavioral data were analyzed for rats with correct cannula placement(s) using analysis of variance (ANOVAs) or t-test, where appropriate, as described in Supplementary Methods. Significant ANOVA main and interaction effects were further investigated using Tukey post-hoc tests, when appropriate. $\alpha$ was set at 0.05 .

\section{Infusion and Quantification of Fluorescent Retrograde Tracers}

In experiment 3, we qualitatively compared the relative density of monosynaptic projections from the VTA and substantia nigra (SN) with the OFC and between the BLA and OFC. Rats were anesthetized as described above. Red Retrobeads (1:4 dilution, $0.5 \mu \mathrm{l}$, Lumafluor, Durham, NC) and Green Retrobeads (undiluted) were infused unilaterally into the left or right BLA $(n=4 ;-2.7 \mathrm{~mm} \mathrm{AP},+/-5.2 \mathrm{~mm}$ $\mathrm{ML},-8.7 \mathrm{~mm} \mathrm{DV}$, from bregma) and OFC $(n=4 ;+3.5 \mathrm{~mm}$ $\mathrm{AP}, \quad+/-3.0 \mathrm{~mm} \mathrm{ML},-5.4 \mathrm{~mm} \mathrm{DV}$, from bregma), respectively, using standard stereotaxic procedures. Microinfusions were delivered over $5 \mathrm{~min}$ with the $33 \mathrm{Ga}$ infusion needle left in place for $10 \mathrm{~min}$ post infusion. Fourteen days later, rats were overdosed, as described above, and transcardially perfused with phosphate-buffered saline followed by $4 \%$ paraformaldehyde. The brains were dissected out, post-fixed, then cryoprotected in 30\% sucrose- $0.1 \%$ sodium azide solution. Coronal sections $(30 \mu \mathrm{m})$ were cut on a freezing microtome. Images were captured at $\times 20$ magnification using a fluorescence microscope. Retrogradely labeled cell bodies were counted bilaterally on representative images in $0.64 \mathrm{~mm}^{2}$ sampling areas using NIH Image J.

\section{RESULTS}

\section{Behavioral History}

Cannula placements were verified in the target brain regions (Supplementary Figure S1). There were no group differences in cocaine intake (mean \pm SEM, $11.09 \pm 0.62 \mathrm{mg} / \mathrm{kg}$ per session) or in lever responding during the selfadministration or extinction phases (see Supplementary Results and Supplementary Table S1).

\section{Reinstatement Testing}

In each experiment, re-exposure to the cocaine-paired context resulted in robust active lever pressing following 
VEH pretreatment, independent of test order (extinction or cocaine-paired context first), treatment order, or the pretreatment administered on the other test day $(\mathrm{F}<2.74$, $P>0.13)$. Therefore, VEH data were collapsed across these variables. Inactive lever responding was low in all experiments and was not altered by the treatment manipulations (all treatment main and interaction effects, $\mathrm{F}<5.69$, $P>0.054$; Supplementary Figure S2 and S3).

\section{Intra-OFC SCH23390 Pretreatment Dose-Dependently Impairs Cocaine Seeking}

At test, bilateral infusions of SCH23390 into the OFC altered drug context-induced reinstatement in a dose- and context-

a
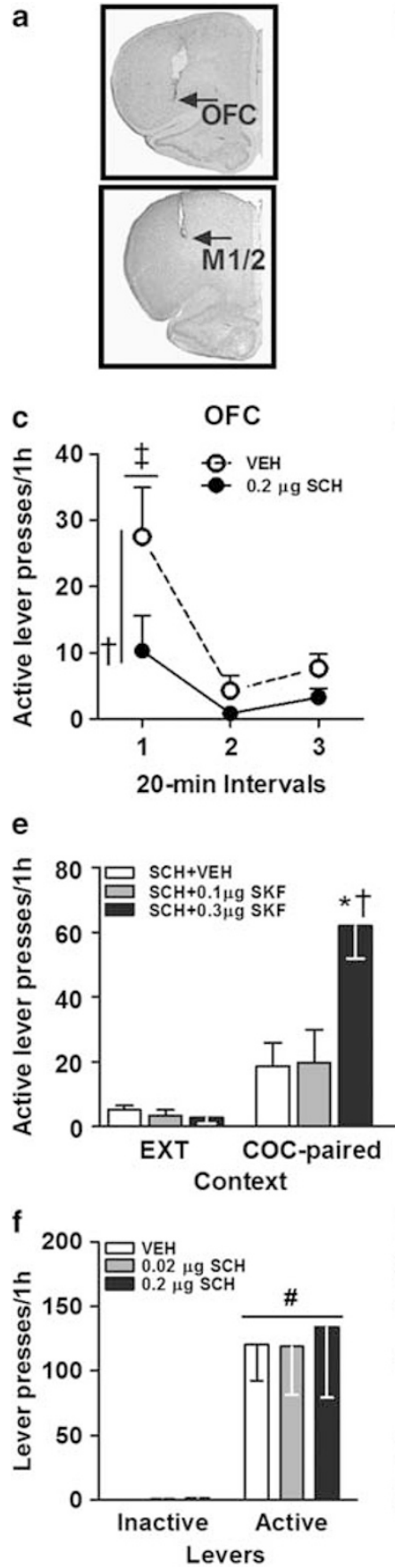

g
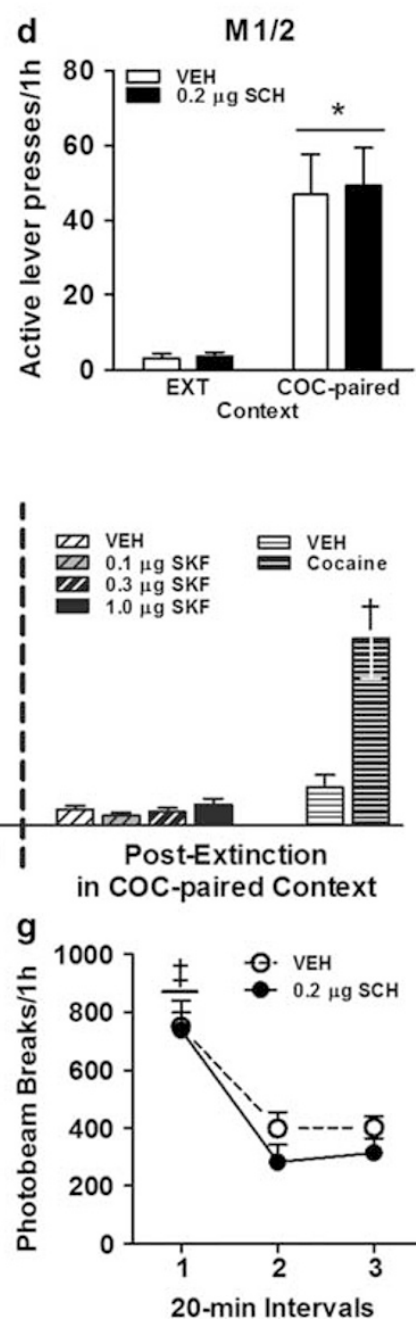

dependent manner (Figure 2b, all main and interaction effects, $\left.\mathrm{F}_{(1-2,20-35)}=8.17-63.87, \quad P=0.0001-0.001\right)$. The $0.2 \mu \mathrm{g}$, but not the $0.02 \mu \mathrm{g}$, dose of SCH23390 attenuated active lever responding in the cocaine-paired context (Tukey test, $P<0.01$ ) relative to $\mathrm{VEH}$. Consequently, there was no difference in active lever responding in the two contexts (Tukey test, $P>0.05$ ). SCH23390 did not alter responding in the extinction context relative to $\mathrm{VEH}$. Additional time-course analysis of responding in the cocaine-paired context indicated that responding declined across time (time main effect, $\mathrm{F}_{(2,16)}=13.78, P=0.0001$; $20 \mathrm{~min}$ interval $1>2-3$, Tukey test, $P<0.05$ ), and the $0.2 \mu \mathrm{g}$ dose of SCH23390 attenuated responding independent of time (Figure $2 \mathrm{c}$, treatment main effect, $\mathrm{F}_{(1,8)}=5.13, P=0.05$; treatment by time interaction effect, $\left.\mathrm{F}_{(2,16)}=1.98, P=0.17\right)$.

\section{Intra-M1/2 SCH23390 Pretreatment Does not Alter Cocaine Seeking}

Bilateral intra-M1/2 infusion of the behaviorally active $(0.2 \mu \mathrm{g})$ dose of $\mathrm{SCH} 23390$ did not alter active lever responding in either context relative to $\mathrm{VEH}$ (Figure 2d, treatment main and interaction effects, $\mathrm{F}<1.26 ; P>0.26$ ). Therefore, following $\mathrm{VEH}$ or SCH 23390 pretreatment, active lever responding was greater in the cocaine-paired context than in the extinction context (context main effect, $\left.\mathrm{F}_{(1,8)}=42.18, P=0.0001\right)$.

\section{Intra-OFC SCH23390 Effect is Surmountable by SKF81297}

The effect of intra-OFC SCH23390 $(0.2 \mu \mathrm{g})$ pretreatment on active lever responding was dose-dependently impaired by SKF81297 co-administration (Figure 2e left; all treatment

Figure 2 Dopamine DI-like receptor stimulation in the OFC, but not the $\mathrm{MI} / 2$, is necessary for drug context-induced cocaine-seeking behavior. The arrows on the photomicrographs in (a) identify the most ventral point of the injection cannula tracts on representative cresyl violet-stained brain sections (see Supplementary Figure SI for placement distribution). Panels b-e depict non-reinforced active lever responses (mean/I h \pm SEM) during testing in the extinction context (EXT) and/or the previously cocainepaired context (COC-paired) following bilateral infusion of phosphatebuffered saline vehicle (VEH) or SCH23390 into the OFC (b and c), $n=8-$ I0/group) or $\mathrm{MI} / 2$ (d), $n=9$ ) or following co-administration of SCH23390 $(0.2 \mu \mathrm{g} / 0.5 \mu \mathrm{l}$ per hemisphere) with $0.1 \%$ DMSO VEH or SKF8I 297 into the OFC (e left, $n=7 /$ group). Panel e right shows the reinstatement of extinguished active lever responses (mean/I h \pm SEM) following intra-OFC VEH or SKF8I297 ( $n=14 /$ group) or following intraperitoneal saline VEH or cocaine ( $10 \mathrm{mg} / \mathrm{kg}, n=7 /$ group) priming. Panel f depicts food-reinforced active and inactive lever responses (mean/l h \pm SEM) following bilateral infusion of $\mathrm{VEH}$ or SCH 23390 into the OFC $(n=9)$. Panel g depicts photobeam breaks (mean/l h \pm SEM) triggered by the movement of subjects in a novel context during a $\mathrm{I}$-h locomotor activity test, following bilateral infusion of $\mathrm{VEH}$ or SCH 23390 into the OFC ( $n=8-10 /$ group). *Represent significant difference relative to responding in the extinction context. ( $b$ and e) Analysis of variance (ANOVA) context simple main effect, Tukey test, $P<0.05$; (d) ANOVA context main effect, $P<0.05$ ). 'Represent significant difference relative to $\mathrm{VEH}$ (b and e): ANOVA treatment simple main effect, Tukey test, $P<0.05$; (c): ANOVA treatment main effect, $P=0.05)$. "Represents significant difference relative to the inactive lever (d): ANOVA lever main effect, $P<0.01$ ). ${ }^{\ddagger}$ Represents significant difference relative to all other time points ( $c$ and $e$ ): ANOVA time simple main effect, interval $\mid>2-3, P<0.05$ ). 


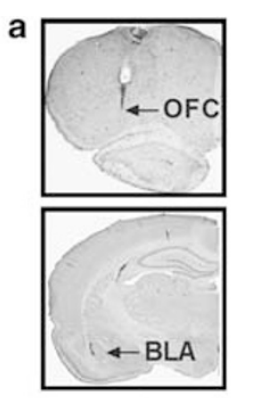

b

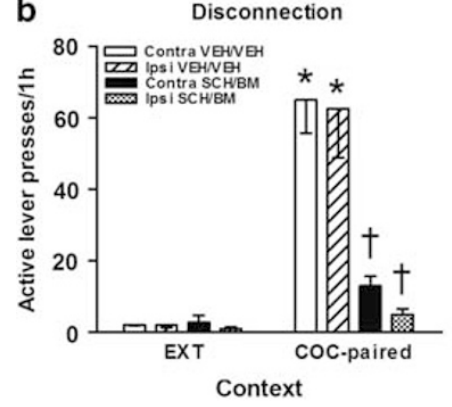

Contralateral
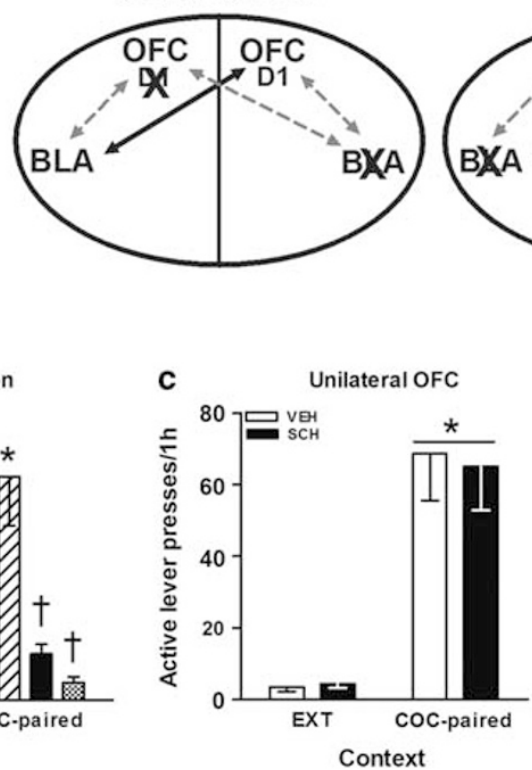

Ipsilateral

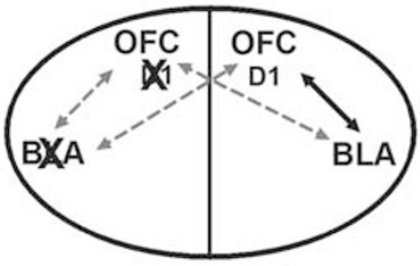

d Unilateral BLA

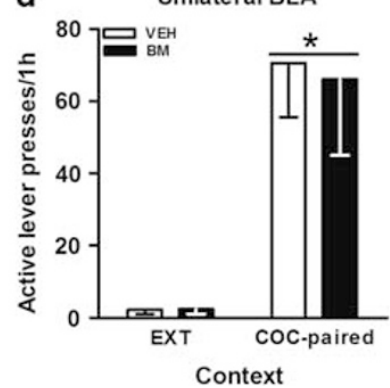

Figure 3 Dopamine DI-like receptor stimulation in the orbitofrontal cortex (OFC) is required for intrahemispheric and interhemispheric interactions between the OFC and basolateral amygdale (BLA) in the control of drug context-induced cocaine-seeking behavior. In panel a, arrows identify the most ventral point of the injection cannula tracts on photomicrographs of representative cresyl violet-stained brain sections (see Supplementary Figure SI for placement distribution) and illustrate the effects of the functional disconnection manipulation on information flow within the putative circuit as depicted on a diagram (solid arrows, intact flow; segmented arrows, disrupted flow). Panels b-d show non-reinforced active lever responses (mean/I h \pm SEM) during testing in the extinction context (EXT context) and the previously cocaine-paired context (COC-paired context). Immediately before testing, rats in the disconnection experiment received infusions of $\mathrm{SCH} 23390(0.2 \mu \mathrm{g} / 0.5 \mu \mathrm{l} /$ hemisphere) unilaterally into the OFC paired with baclofen + muscimol (BM; I06.8/5.7 ng, $0.5 \mu \mathrm{l} /$ hemisphere) into the contralateral or ipsilateral BLA ( $n=12$ and I0/group, respectively) or vehicle $(V E H)$ into the contralateral or ipsilateral OFC and BLA (b). Rats in the unilateral control experiments received infusions of $0.2 \mu \mathrm{g}$ of SCH 23390 or VEH into the OFC (c), $n=1 \mathrm{I}$ ) or I 06.8 / $5.7 \mathrm{ng} B M$ or $\mathrm{VEH}$ into the BLA (d), $n=7$ ). *Represents significant difference relative to responding in the extinction context. (b) Analysis of variance (ANOVA) context simple main effect, Tukey test, $P<0.0$; ; $(c$ and d) ANOVA context main effect, $P<0.05$ ). "Represents significant difference relative to VEH pretreatment. (b) ANOVA treatment simple main effect, Tukey test, $P<0.0 \mathrm{I}$ ).

main and interaction effects, $F_{(1-2,25)}=4.91-31.62$, $P=0.001-0.016)$. Co-administration of the $0.3 \mu \mathrm{g}$, but not the $0.1 \mu \mathrm{g}$, dose of SKF81297 with SCH23390 increased active lever responding in the cocaine-paired context relative to the extinction context (Tukey test, $P<0.01$ ) and relative to $\mathrm{SCH} 23390$ alone (Tukey test, $P<0.01$ ), without altering responding in the extinction context.

Importantly, bilateral intra-OFC pretreatment with SKF81297 was insufficient to reinstate active lever responding following extinction in the cocaine-paired context (Figure 2e right), relative to $\operatorname{VEH}\left(\mathrm{F}_{(3,39)}=1.21, P=0.32\right)$. Conversely, cocaine $(10 \mathrm{mg} / \mathrm{kg}$, i.p.) priming was sufficient to increase active lever responding (Figure 2e right; $\left.t_{(13)}=-2.97, P=0.01\right)$, relative to $\mathrm{VEH}$, demonstrating the continued capacity of the groups for reinstatement.

\section{Intra-OFC SCH23390 Effects do not Reflect Motor Impairment}

Intra-OFC SCH23390 did not alter food-reinforced instrumental motor behavior (Figure 2f) or general locomotor activity (Figure 2g), relative to $\mathrm{VEH}$ pretreatment. Active lever responding was significantly greater than inactive lever responding during the food-reinforced test sessions (lever main effect, $\mathrm{F}_{(1,17)}=17.32, P=0.004$ ) independent of SCH23390 (0.02 or $0.2 \mu \mathrm{g})$ pretreatment (treatment main and interaction effects, Fs $<0.06, P>0.69$ ). The number of photobeam breaks during the $1 \mathrm{~h}$ locomotor activity test session decreased across time (time main effect, $\mathrm{F}_{(2,20)}=28.29, \quad P=0.001 ; 20 \mathrm{~min}$ interval 1>2-3; Tukey test, $P<0.01)$ independent of SCH23390 (0.2 $\mu \mathrm{g})$ pretreatment (treatment main and interaction effects, Fs $<1.09$, $P>0.32)$.

\section{VTA-OFC-BLA Functional Disconnection has Superadditive Effect on Cocaine Seeking}

Intra-OFC SCH23390+intra-BLA BM pretreatment impaired active lever responding relative to $\mathrm{VEH}+\mathrm{VEH}$ pretreatment in a context-specific manner following either contralateral or ipsilateral administration (treatment and context main and interaction effects, $F_{(1,20)}=43.23-74.10$, $P=0.0001$; surgery condition main and interaction effects, $\mathrm{F} \leqslant 0.52, \quad P \geqslant 0.48$; Figure $3 \mathrm{~b}$ ). Following ipsilateral or contralateral $\mathrm{VEH}+\mathrm{VEH}$ pretreatment, active lever responding was greater in the cocaine-paired context than in the extinction context (Tukey tests, $P<0.01$ ). Ipsilateral or contralateral SCH $23390+\mathrm{BM}$ pretreatment attenuated active lever responding relative to $\mathrm{VEH}+\mathrm{VEH}$ pretreatment in the cocaine-paired context (Tukey tests, $P<0.01$ ) without altering responding in the extinction context. Therefore, following SCH23390 + BM pretreatment, there was no difference in active lever responding in the two contexts (Tukey tests, $P>0.05$ ). The effect of SCH23390+ $\mathrm{BM}$ pretreatment was independent of the particular hemisphere in which SCH23390 was administered into the OFC 
$\left(t_{(20)}=0.79, P=0.44\right)$ or BM was administered into the BLA $\left(t_{(20)}=0.16, P=0.88\right)$.

Unlike functional disconnection, unilateral intra-OFC SCH23390 (Figure 3c, treatment main and interaction effects, $\mathrm{F}<0.07, P>0.79$ ) or intra-BLA BM (Figure $3 \mathrm{~d}$, treatment main and interaction effects, $\mathrm{F}<0.06, P>0.81$ ) pretreatment failed to alter active lever responding in either context relative to $\mathrm{VEH}$. Thus, active lever responding was greater in the cocaine-paired context than in the extinction context independent of treatment (context main effect, OFC: $\mathrm{F}_{(1,10)}=31.02, P<0.001$; BLA: $\left.\mathrm{F}_{(1,6)}=17.72, P=0.006\right)$.

\section{Distribution of Retrogradely Labeled Cell Bodies}

Retrograde tracing data illustrating select projections between the elements of the putative VTA-OFC-BLA circuit are shown in Figure 4. Retrogradely labeled cell bodies were detected in the ipsilateral and contralateral VTA (Figure 4a) and BLA (Figure 4c), but not in the SN (Figure 4b), following unilateral Green Retrobeads microinfusion into the OFC. In addition, retrogradely labeled cell bodies were detected in the ipsilateral and contralateral OFC (Figure 4d) following unilateral Red Retrobeads microinfusion into the BLA.

\section{DISCUSSION}

Findings in the current study provide the first evidence that a VTA-OFC-BLA neural circuit regulates the ability of a drug-paired environmental context to elicit cocaine-seeking behavior. We examined this circuitry using a three-step approach. In experiment 1 , we demonstrated that dopamine D1-like receptor stimulation in the OFC is required for drug context-induced cocaine-seeking behavior. In experiment 2, we further showed that dopamine D1-like receptor stimulation in the OFC is critical for interhemispheric or intrahemispheric communication between the OFC and BLA that controls this behavior. Finally, in experiment 3, we confirmed that the VTA, but not the $\mathrm{SN}$, sends dense bilateral projections to the OFC. In addition, the OFC has bilateral and reciprocal connections with the BLA. Taken together, these findings support the hypothesis that input from the VTA-via the stimulation of dopamine D1-like receptors in the $\mathrm{OFC}$-gates communication between the OFC and BLA that promotes the reinstatement of drug context-induced cocaine-seeking behavior.

Dopamine D1-like receptor stimulation in the OFC critically regulates the motivational effects of drug-paired contextual stimuli on cocaine-seeking behavior. The effect of SCH23390 did not reflect non-specific motor deficits, given that this manipulation failed to alter inactive lever responding in either context (Supplementary Figure S2), food-reinforced instrumental performance (Figure 2f) or general locomotor activity in a novel context (Figure $2 \mathrm{~g}$ ). It is unlikely that SCH23390 impaired context discrimination as it did not enhance active lever responding in the extinction context (Figure 2b). Similarly, it is unlikely that SCH23390 facilitated extinction learning given that it did not increase the rate of decline in active lever responding during the test session in the cocaine context (Figure 2c). Furthermore, the effect of SCH23390 was anatomically specific to the OFC in that bilateral infusions of SCH23390 a

$-4.9$
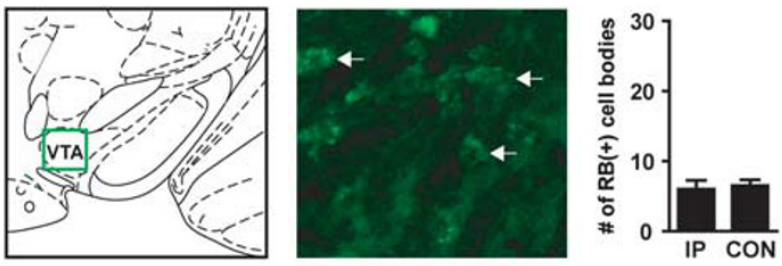

b
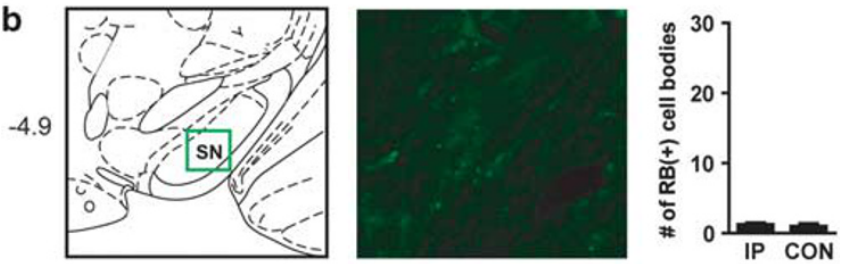

C
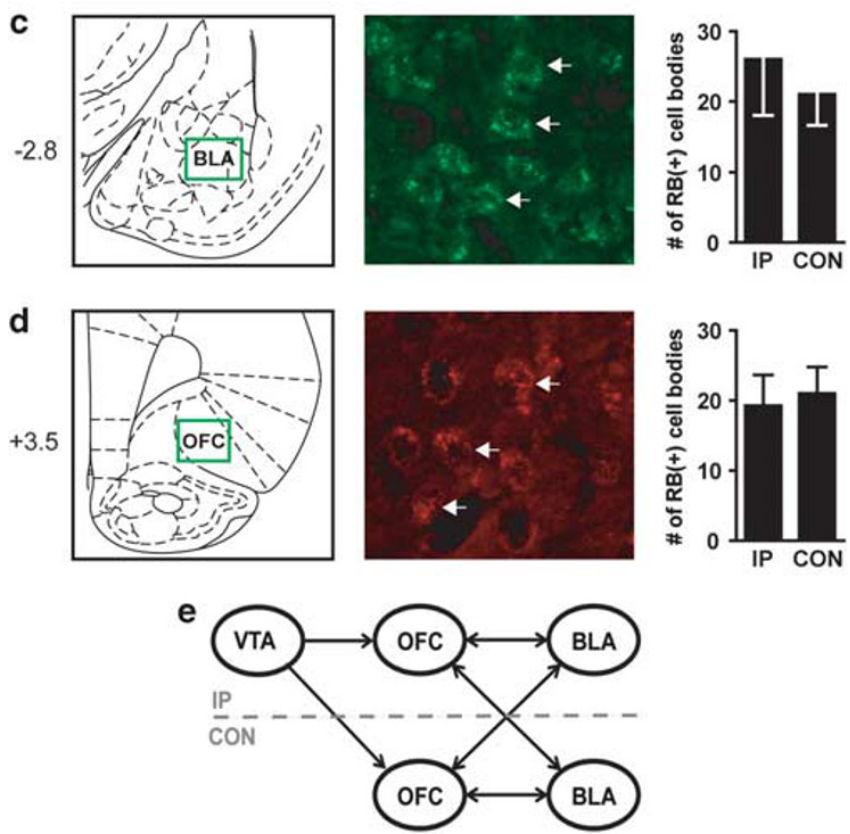

Figure 4 Anatomical connections within a VTA-OFC-BLA (VTA, ventral tegmental area; OFC, orbitofrontal cortex; BLA, basolateral amygdala) neural circuit as indicated by retrograde tracing (a-d) and summarized on a diagram (e). Red and Green Retrobeads were infused into the OFC or BLA (see Supplementary Figure SI for placement distribution) and retrogradely labeled cell bodies were quantified bilaterally in the areas identified on the schematics adapted from the rat brain atlas of Paxinos and Watson (1997). Numbers to the left of the schematics indicate the distance from bregma in millimeters. The arrows on the photomicrographs identify representative retrogradely labeled cell bodies ( $\times 20$ magnification). The graphs depict the total number of retrobead-positive cell bodies $\left(\mathrm{RB}(+)\right.$; mean $/ 0.64 \mathrm{~mm}^{2}$ sampling area \pm SEM) in the ipsilateral (IP) and contralateral (CON) VTA (a), substantia nigra (SN) (b), and BLA (c) following unilateral Green Retrobeads microinfusion into the left or right OFC $(n=4)$ as well as in the ipsilateral and contralateral OFC (d) following unilateral Red Retrobeads microinfusion into the left or right $\mathrm{BLA}(n=4)$.

into the dorsally adjacent M1/2 region did not alter cocaine seeking (Figure 2d) similar to other reward-related motor behaviors in previous studies (Hosp et al, 2011; Luft and Schwarz, 2009; Molina-Luna et al, 2009). Although SCH23390 has been routinely used to ascertain the functional contribution of dopamine D1-like receptors, it also acts as a serotonin $5-\mathrm{HT}_{2 \mathrm{C}}$ receptor agonist (Kalkman et al, 1998; Rupniak et al, 1986), and systemic $5-\mathrm{HT}_{2 \mathrm{C}}$ receptor stimulation attenuates explicit cue- and context-induced 
cocaine-seeking behaviors (Neisewander and Acosta, 2007; Fletcher et al, 2008). Therefore, it is significant that the effect of SCH23390 in the OFC could be overcome by co-administration of the D1-like receptor agonist, SKF81297 (Figure $2 \mathrm{e}$ left), at a dose that alone failed to reinstate cocaine-seeking behavior in rats that could exhibit reinstatement in response to cocaine priming (Figure $2 \mathrm{e}$ right). Together, these results indicate that D1-like receptor stimulation is necessary, but not sufficient, for the reinstatement of cocaine-seeking behavior, similar to instrumental responding maintained by conditioned reinforcement (Winstanley et al, 2006). Conditioned stimuli elicit prolonged increases in dopamine neurotransmission (Garris et al, 1993; Sesack et al, 1998), which may permit the OFC to maintain the internal motivational representation of cocaine-paired contextual stimuli by facilitating glutamatergic inputs to the OFC (Cepeda et al, 1998a; Lapish et al, 2006; Schultz, 2002; Seamans et al, 2003). Furthermore, this phenomenon likely involves glutamatergic afferents from the BLA (Fuchs et al, 2005, 2004; Lasseter et al, 2009, 2011). Interestingly, the training protocol used in the present study fails to elicit significant context-induced reinstatement of food-seeking behavior, as shown previously (Xie et al, 2010). Thus, contextual conditioning with natural reinforcers may be less robust due to overshadowing by explicit food-related/conditioned stimuli or qualitatively different due to background conditioning, relative to contextual conditioning with intravenous drug reinforcers.

Given that the VTA is the primary source of dopamine to the OFC (Figure 4a; Berger et al, 1991), unilateral SCH23390-induced D1-like receptor antagonism in the OFC in combination with BM-induced functional inactivation of the contralateral or ipsilateral BLA could be used to disconnect and thereby probe the putative VTA-OFC-BLA circuit in the present study (Figure 3a). Contralateral or ipsilateral intra-OFC SCH23390 + intra-BLA BM pretreatment attenuated drug context-induced cocaine-seeking behavior relative to $\mathrm{VEH}$ in a context- and lever-specific manner (Figure 3b and Supplementary Figure S3). These findings expand upon our previous study (Lasseter et al, 2011), in which BM-induced functional disconnection of the OFC and BLA inhibited drug context-induced reinstatement of cocaine-seeking behavior without altering food-reinforced instrumental responding or general motor activity. These findings also add to a larger literature that indicates that the OFC and BLA are critical for explicit cue- and drug context-induced cocaine-seeking behaviors (Atkins et al, 2008; Crombag et al, 2008; Fuchs et al, 2005, 2004, 2008; Grimm and See, 2000; Hamlin et al, 2008; Kantak et al, 2002; Lasseter et al, 2009, 2011; McLaughlin and See, 2003; Neisewander et al, 2000; See et al, 2001; Zavala et al, 2008).

Ipsilateral and contralateral OFC-BLA manipulations similarly impaired drug context-induced cocaine seeking (Figure $3 \mathrm{~b}$ ), suggesting that interactions within the putative VTA-OFC-BLA circuit are complex. Unilateral manipulation of the OFC (Figure 3c) or BLA alone (Figure 3d) failed to alter drug context-induced cocaine-seeking behavior, consistent with previous reports (Everitt et al, 1991; Fuchs et al, 2007; Saddoris et al, 2005). Hence, the robust attenuation in cocaine seeking following ipsilateral or contralateral OFC-BLA manipulation was superadditive compared with the effects of independent, unilateral manipulations of the OFC plus BLA. A superadditive effect following ipsilateral manipulation may occur when functional impairment requires disruption of neuronal function beyond a theoretical threshold and indicate independent contribution by the brain regions. More likely, dopamine from the VTA regulates interhemispheric and intrahemispheric communication between the OFC and BLA via D1like receptor stimulation in the OFC. This interpretation is supported by anatomical evidence from previous studies (Berger et al, 1991; Dunnett and Robbins, 1992; Frankle et al, 2006; Reynolds et al, 2006; Sesack and Grace, 2010; Watabe-Uchida et al, 2012) and from our retrograde tracing experiment indicating that the VTA (Figure 4a), but not the SN (Figure 4b), projects to the OFC. Moreover, the OFC and BLA share direct, reciprocal intrahemispheric and interhemispheric connections (Figure 4c and d; Carmichael and Price, 1995a; Ghashghaei and Barbas, 2002; Krettek and Price, 1977; McDonald, 1991) as well as indirect connections relayed through the mediodorsal thalamus (Cavada et al, 2000; Demeter et al, 1990; Ghashghaei and Barbas, 2002; Macey et al, 2003; Miyashita et al, 2007). Therefore, we propose that an intricate, intra- and interhemispheric VTAOFC-BLA neural circuit controls drug context-induced motivation for cocaine.

Notably, the disconnection procedure does not permit one to identify the exact sequence of information processing within a neural circuit. Future research will be necessary in order to parse out the precise microcircuits by which the VTA, OFC and BLA interact to promote drug contextinduced cocaine seeking. For instance, although dopaminergic input from the VTA to the OFC controls neuronal activity (Aou et al, 1983), back-projections from the OFC to the VTA may also regulate dopaminergic input to the OFC itself and to the BLA (Takahashi et al, 2009). In particular, input from the VTA to the BLA may be important for processing the motivational effects of cocaine-paired contextual stimuli, given that dopamine D1-like receptor antagonism in the BLA prevents explicit drug-paired cues from eliciting cocaineseeking behavior (Alleweireldt et al, 2005; Berglind et al, 2006; Mashhoon et al, 2009; See et al, 2001).

Importantly, the VTA-OFC-BLA neural circuit is likely a component of a larger neural system. Within this system, the OFC and BLA are well-positioned to integrate contextrelevant multi-modal sensory input from sensory cortices with reward-related information from other mesocorticolimbic brain regions in order to guide goal-directed behaviors (Brog et al, 1993; Carmichael and Price, 1995b; Fuchs et al, 2008; McDannald et al, 2004; Price, 1986; Sah et al, 2003; Xie et al, 2010). For instance, in addition to dopaminergic input from the VTA to the OFC and BLA, glutamatergic inputs from the OFC and BLA and dopaminergic input from the VTA converge on dendritic spines of nucleus accumbens (NAc) medium spiny neurons (Kelley et al, 1982; Bouyer et al, 1984; Haber et al, 1995). The NAc may then gate the throughput of information to the limbic loop of the basal ganglia that promotes the expression of goal-directed behavior (Cepeda et al, 1993; Cepeda and Levine, 1998b; Di Ciano and Everitt, 2004; Kiyatkin and Rebec, 1996). In concert with this, unilateral inactivation of the BLA paired with dopamine D1-like receptor antagonism in the NAc reduces behavioral responding to sucrosepredictive cues (Ambroggi et al, 2008), and optogenetic 
inhibition of glutamatergic projections from the BLA to the NAc prevents cue-maintained sucrose consumption (Stuber et al, 2011).

In conclusion, results from the current study suggest that a mesocorticolimbic subcircuit exists in which dopaminergic input from the VTA to the OFC, via dopamine D1-like receptor stimulation, regulates intra- and interhemispheric interactions between the OFC and BLA that promote drug context-induced cocaine seeking. From an addiction treatment perspective, it will be important to systematically identify the brain regions with which the newly characterized VTA-OFC-BLA circuit interacts. Complementing this approach, future studies will need to characterize putative drug-induced and experience-based neuroadaptations within the circuitry that enhance cue reactivity and the propensity for cue-induced relapse in substance abusers.

\section{FUNDING AND DISCLOSURE}

The authors declare no conflict of interest.

\section{ACKNOWLEDGEMENTS}

The authors thank Albert R. Newsome and Andrew M. Reittinger for their excellent technical assistance and insightful comments on an earlier version of this manuscript. This work was supported by National Institute on Drug Abuse (NIDA) F31 DA028051 (HL), F31 DA034391 (AW), R01 DA017673, and R01 DA025646.

\section{REFERENCES}

Alleweireldt AT, Hobbs RJ, Taylor AR, Neisewander JL (2005). Effects of SCH-23390 infused into the amygdala or adjacent cortex and basal ganglia on cocaine seeking and self-administration in rats. Neuropsychopharmacology 31: 363-374.

Ambroggi F, Ishikawa A, Fields HL, Nicola SM (2008). Basolateral amygdala neurons facilitate reward-seeking behavior by exciting nucleus accumbens neurons. Neuron 59: 648-661.

Aou S, Oomura Y, Nishino H, Inokuchi A, Mizuno Y (1983). Influence of catecholamines on reward-related neuronal activity in monkey orbitofrontal cortex. Brain Res 267: 165-170.

Atkins AL, Mashhoon Y, Kantak KM (2008). Hippocampal regulation of contextual cue-induced reinstatement of cocaineseeking behavior. Pharmacol Biochem Behav 90: 481-491.

Berger B, Gaspar P, Verney C (1991). Dopaminergic innervation of the cerebral cortex: unexpected differences between rodents and primates. Trends Neurosci 14: 21-27.

Berglind WJ, Case JM, Parker MP, Fuchs RA, See RE (2006). Dopamine D1 or D2 receptor antagonism within the basolateral amygdala differentially alters the acquisition of cocaine-cue associations necessary for cue-induced reinstatement of cocaineseeking. Neuroscience 137: 699-706.

Bouyer JJ, Park DH, Joh TH, Pickel VM (1984). Chemical and structural analysis of the relation between cortical inputs and tyrosine hydroxylase-containing terminals in rat neostriatum. Brain Res 302: 267-275.

Brog JS, Salyapongse A, Deutch AY, Zahm DS (1993). The patterns of afferent innervation of the core and shell in the 'accumbens' part of the rat ventral striatum: immunohistochemical detection of retrogradely transported fluoro-gold. J Comp Neurol 338: $255-278$.
Capriles N, Rodaros D, Sorge RE, Stewart J (2003). A role for the prefrontal cortex in stress- and cocaine-induced reinstatement of cocaine seeking in rats. Psychopharmacology 168: 66-74.

Carmichael ST, Price JL (1995a). Limbic connections of the orbital and medial prefrontal cortex in macaque monkeys. J Comp Neurol 363: 615-641.

Carmichael ST, Price JL (1995b). Sensory and premotor connections of the orbital and medial prefrontal cortex of macaque monkeys. J Comp Neurol 363: 642-664.

Cavada C, Company T, Tejedor J, Cruz-Rizzolo RJ, ReinosoSuarez F (2000). The anatomical connections of the macaque monkey orbitofrontal cortex. A review.. Cereb Cortex 10: 220-242.

Cepeda C, Buchwald NA, Levine MS (1993). Neuromodulatory actions of dopamine in the neostriatum are dependent upon the excitatory amino acid receptor subtypes activated. Proc Natl Acad Sci U S A 90: 9576-9580.

Cepeda C, Colwell CS, Itri JN, Chandler SH, Levine MS (1998a). Dopaminergic modulation of NMDA-induced whole cell currents in neostriatal neurons in slices: contribution of calcium conductances. J Neurophysiol 79: 82-94.

Cepeda C, Levine MS (1998b). Dopamine and N-methyl-Daspartate receptor interactions in the neostriatum. Dev Neurosci 20: $1-18$.

Cetin T, Freudenberg F, Fuchtemeier M, Koch M (2004). Dopamine in the orbitofrontal cortex regulates operant responding under a progressive ratio of reinforcement in rats. Neurosci Lett 370: 114-117.

Childress AR, Mozley PD, McElgin W, Fitzgerald J, Reivich M, O’Brien CP (1999). Limbic activation during cue-induced cocaine craving. Am J Psychiatry 156: 11-18.

Crombag HS, Bossert JM, Koya E, Shaham Y (2008). Contextinduced relapse to drug seeking: a review. Philos Trans $R$ Soc Lond B Biol Sci 363: 3233-3243.

Crombag HS, Grimm JW, Shaham Y (2002). Effect of dopamine receptor antagonists on renewal of cocaine seeking by reexposure to drug-associated contextual cues. Neuropsychopharmacology 27: 1006-1015.

Dalley JW, Cardinal RN, Robbins TW (2004). Prefrontal executive and cognitive functions in rodents: neural and neurochemical substrates. Neurosci Biobehav Rev 28: 771-784.

Demeter S, Rosene DL, Van Hoesen GW (1990). Fields of origin and pathways of the interhemispheric commissures in the temporal lobe of macaques. J Comp Neurol 302: 29-53.

Di Ciano P, Everitt BJ (2004). Direct interactions between the basolateral amygdala and nucleus accumbens core underlie cocaine-seeking behavior by rats. J Neurosci 24: 7167-7173.

Duncan E, Boshoven W, Harenski K, Fiallos A, Tracy H, Jovanovic $\mathrm{T}$ et al (2007). An fMRI study of the interaction of stress and cocaine cues on cocaine craving in cocaine-dependent men. Am J Addict 16: 174-182.

Dunnett SB, Robbins TW (1992). The functional role of mesotelencephalic dopamine systems. Biol Rev Camb Philos Soc 67: 491-518.

Everitt BJ, Morris KA, O'Brien A, Robbins TW (1991). The basolateral amygdala-ventral striatal system and conditioned place preference: further evidence of limbic-striatal interactions underlying reward-related processes. Neuroscience 42: $1-18$.

Fletcher PJ, Rizos Z, Sinyard J, Tampakeras M, Higgins GA (2008). The 5-HT2C receptor agonist Ro60-0175 reduces cocaine selfadministration and reinstatement induced by the stressor yohimbine, and contextual cues. Neuropsychopharmacology 33: $1402-1412$.

Frankle WG, Laruelle M, Haber SN (2006). Prefrontal cortical projections to the midbrain in primates: evidence for a sparse connection. Neuropsychopharmacology 31: 1627-1636. 
Fuchs RA, Eaddy JL, Su ZI, Bell GH (2007). Interactions of the basolateral amygdala with the dorsal hippocampus and dorsomedial prefrontal cortex regulate drug context-induced reinstatement of cocaine-seeking in rats. Eur J Neurosci 26: 487-498.

Fuchs RA, Evans KA, Ledford CC, Parker MP, Case JM, Mehta RH et al (2005). The role of the dorsomedial prefrontal cortex, basolateral amygdala, and dorsal hippocampus in contextual reinstatement of cocaine seeking in rats. Neuropsychopharmacology 30: 296-309.

Fuchs RA, Evans KA, Parker MP, See RE (2004). Differential involvement of orbitofrontal cortex subregions in conditioned cue-induced and cocaine-primed reinstatement of cocaine seeking in rats. J Neurosci 24: 6600-6610.

Fuchs RA, Ramirez DR, Bell GH (2008). Nucleus accumbens shell and core involvement in drug context-induced reinstatement of cocaine seeking in rats. Psychopharmacology 200: 545-556.

Garris PA, Collins LB, Jones SR, Wightman RM (1993). Evoked extracellular dopamine in vivo in the medial prefrontal cortex. I Neurochem 61: 637-647.

Geisler S, Derst C, Veh RW, Zahm DS (2007). Glutamatergic afferents of the ventral tegmental area in the rat. J Neurosci 27: $5730-5743$

Ghashghaei HT, Barbas H (2002). Pathways for emotion: interactions of prefrontal and anterior temporal pathways in the amygdala of the rhesus monkey. Neuroscience 115: 1261-1279.

Grant S, London ED, Newlin DB, Villemagne VL, Liu X, Contoreggi C et al (1996). Activation of memory circuits during cue-elicited cocaine craving. Proc Natl Acad Sci USA 93: 12040-12045.

Grimm JW, See RE (2000). Dissociation of primary and secondary reward-relevant limbic nuclei in an animal model of relapse. Neuropsychopharmacology 22: 473-479.

Haber SN, Kunishio K, Mizobuchi M, Lynd-Balta E (1995). The orbital and medial prefrontal circuit through the primate basal ganglia. J Neurosci 15: 4851-4867.

Hamlin AS, Clemens KJ, McNally GP (2008). Renewal of extinguished cocaine-seeking. Neuroscience 151: 659-670.

Hosp JA, Pekanovic A, Rioult-Pedotti MS, Luft AR (2011). Dopaminergic projections from midbrain to primary motor cortex mediate motor skill learning. J Neurosci 31: 2481-2487.

Kalkman HO, Neumann V, Hoyer D, Tricklebank MD (1998). The role of alpha2-adrenoceptor antagonism in the anti-cataleptic properties of the atypical neuroleptic agent, clozapine, in the rat. Br J Pharmacol 124: 1550-1556.

Kantak KM, Black Y, Valencia E, Green-Jordan K, Eichenbaum HB (2002). Dissociable effects of lidocaine inactivation of the rostral and caudal basolateral amygdala on the maintenance and reinstatement of cocaine-seeking behavior in rats. $J$ Neurosci 22: 1126-1136.

Kelley AE, Domesick VB, Nauta WJ (1982). The amygdalostriatal projection in the rat-an anatomical study by anterograde and retrograde tracing methods. Neuroscience 7: 615-630.

Kheramin S, Body S, Ho MY, Velazquez-Martinez DN, Bradshaw CM, Szabadi E et al (2004). Effects of orbital prefrontal cortex dopamine depletion on inter-temporal choice: a quantitative analysis. Psychopharmacology 175: 206-214.

Kiyatkin EA, Rebec GV (1996). Dopaminergic modulation of glutamate-induced excitations of neurons in the neostriatum and nucleus accumbens of awake, unrestrained rats. J Neurophysiol 75: 142-153.

Krettek JE, Price JL (1977). Projections from the amygdaloid complex to the cerebral cortex and thalamus in the rat and cat. J Comp Neurol 172: 687-722.

Lapish CC, Seamans JK, Chandler LJ (2006). Glutamate-dopamine cotransmission and reward processing in addiction. Alcohol Clin Exp Res 30: 1451-1465.

Lasseter HC, Ramirez DR, Xie X, Fuchs RA (2009). Involvement of the lateral orbitofrontal cortex in drug context-induced re- instatement of cocaine-seeking behavior in rats. Eur J Neurosci 30: $1370-1381$.

Lasseter HC, Wells AM, Xie X, Fuchs RA (2011). Interaction of the basolateral amygdala and orbitofrontal cortex is critical for drug context-induced reinstatement of cocaine-seeking behavior in rats. Neuropsychopharmacology 36: 711-720.

London ED, Bonson KR, Ernst M, Grant S (1999). Brain imaging studies of cocaine abuse: implications for medication development. Crit Rev Neurobiol 13: 227-242.

Luft AR, Schwarz S (2009). Dopaminergic signals in primary motor cortex. Int J Dev Neurosci 27: 415-421.

Macey DJ, Smith HR, Nader MA, Porrino LJ (2003). Chronic cocaine self-administration upregulates the norepinephrine transporter and alters functional activity in the bed nucleus of the stria terminalis of the rhesus monkey. J Neurosci 23: $12-16$.

Mashhoon Y, Tsikitas LA, Kantak KM (2009). Dissociable effects of cocaine-seeking behavior following D1 receptor activation and blockade within the caudal and rostral basolateral amygdala in rats. Eur J Neurosci 29: 1641-1653.

McDannald M, Kerfoot E, Gallagher M, Holland PC (2004). Amygdala central nucleus function is necessary for learning but not expression of conditioned visual orienting. Eur J Neurosci 20: 240-248.

McDonald AJ (1991). Organization of amygdaloid projections to the prefrontal cortex and associated striatum in the rat Neuroscience 44: 1-14.

McLaughlin J, See RE (2003). Selective inactivation of the dorsomedial prefrontal cortex and the basolateral amygdala attenuates conditioned-cued reinstatement of extinguished cocaine-seeking behavior in rats. Psychopharmacology 168: $57-65$.

Miyashita T, Ichinohe N, Rockland KS (2007). Differential modes of termination of amygdalothalamic and amygdalocortical projections in the monkey. J Comp Neurol 502: 309-324.

Molina-Luna K, Pekanovic A, Rohrich S, Hertler B, SchubringGiese M, Rioult-Pedotti MS et al (2009). Dopamine in motor cortex is necessary for skill learning and synaptic plasticity. PLoS One 4: e7082.

Neisewander JL, Acosta J (2007). Stimulation of 5-HT2C receptors attenuates cue and cocaine-primed reinstatement of cocaineseeking behavior in rats. Behav Pharmacol 18: 791-800.

Neisewander JL, Baker DA, Fuchs RA, Tran-Nguyen LT, Palmer A, Marshall JF (2000). Fos protein expression and cocaine-seeking behavior in rats after exposure to a cocaine self-administration environment. J Neurosci 20: 798-805.

Paxinos G, Watson C (1997). The rat brain in stereotaxic coordinates, compact, 3rd edn. Academic Press: San Diego, CA.

Price JL (1986). Subcortical projections from the amygdaloid complex. Adv Exp Med Biol 203: 19-33.

Ragozzino ME, Detrick S, Kesner RP (1999). Involvement of the prelimbic-infralimbic areas of the rodent prefrontal cortex in behavioral flexibility for place and response learning. $J$ Neurosci 19: 4585-4594.

Reynolds SM, Geisler S, Berod A, Zahm DS (2006). Neurotensin antagonist acutely and robustly attenuates locomotion that accompanies stimulation of a neurotensin-containing pathway from rostrobasal forebrain to the ventral tegmental area. Eur J Neurosci 24: 188-196.

Rupniak NM, Briggs RS, Petersen MM, Mann S, Reavill C, Jenner P et al (1986). Differential alterations in striatal acetylcholine function in rats during 12 months' continuous administration of haloperidol, sulpiride or clozapine. Clin Neuropharmacol 9: 282-292.

Saddoris MP, Gallagher M, Schoenbaum G (2005). Rapid associative encoding in basolateral amygdala depends on connections with orbitofrontal cortex. Neuron 46: 321-331. 
Sah P, Faber ES, Lopez De Armentia M, Power J (2003). The amygdaloid complex: anatomy and physiology. Physiol Rev 83: 803-834.

Schultz W (2002). Getting formal with dopamine and reward. Neuron 36: 241-263.

Seamans JK, Nogueira L, Lavin A (2003). Synaptic basis of persistent activity in prefrontal cortex in vivo and in organotypic cultures. Cereb Cortex 13: 1242-1250.

See RE, Kruzich PJ, Grimm JW (2001). Dopamine, but not glutamate, receptor blockade in the basolateral amygdala attenuates conditioned reward in a rat model of relapse to cocaine-seeking behavior. Psychopharmacology 154: 301-310.

Sesack SR, Grace AA (2010). Cortico-basal ganglia reward network: microcircuitry. Neuropsychopharmacology 35: 27-47.

Sesack SR, Hawrylak VA, Guido MA, Levey AI (1998). Cellular and subcellular localization of the dopamine transporter in rat cortex. Adv Pharmacol 42: 171-174.

Stuber GD, Sparta DR, Stamatakis AM, van Leeuwen WA, Hardjoprajitno JE, Cho S et al (2011). Excitatory transmission from the amygdala to nucleus accumbens facilitates reward seeking. Nature 475: 377-380.

Takahashi YK, Roesch MR, Stalnaker TA, Haney RZ, Calu DJ, Taylor AR et al (2009). The orbitofrontal cortex and ventral tegmental area are necessary for learning from unexpected outcomes. Neuron 62: 269-280.
Ward SJ, Rosenberg M, Dykstra LA, Walker EA (2009). The CB antagonist rimonabant (SR141716) blocks cue-induced reinstatement of cocaine seeking and other context and extinction phenomena predictive of relapse. Drug Alcohol Depend 105: 248-255.

Watabe-Uchida M, Zhu L, Ogawa SK, Vamanrao A, Uchida N (2012). Whole-brain mapping of direct inputs to midbrain dopamine neurons. Neuron 74: 858-873.

Winstanley CA, Theobald DE, Dalley JW, Cardinal RN, Robbins TW (2006). Double dissociation between serotonergic and dopaminergic modulation of medial prefrontal and orbitofrontal cortex during a test of impulsive choice. Cereb Cortex 16: 106-114.

Winter S, Dieckmann M, Schwabe K (2009). Dopamine in the prefrontal cortex regulates rats behavioral flexibility to changing reward value. Behav Brain Res 198: 206-213.

Xie X, Lasseter HC, Ramirez DR, Ponds KL, Wells AM, Fuchs RA (2010). Subregion-specific role of glutamate receptors in the nucleus accumbens on drug context-induced reinstatement of cocaine-seeking behavior in rats. Addict Biol 17: 287-299.

Zavala AR, Osredkar T, Joyce JN, Neisewander JL (2008). Upregulation of Arc mRNA expression in the prefrontal cortex following cue-induced reinstatement of extinguished cocaineseeking behavior. Synapse 62: 421-431.

Supplementary Information accompanies the paper on the Neuropsychopharmacology website (http://www.nature.com/npp) 